\title{
Service model for the management of industrial environments. Dynamic reconfiguration of production elements
}

\author{
Diego Marcos-Jorquera, Francisco Maciá-Pérez, \\ Virgilio Gilart-Iglesias, Juan Antonio Gil-Martínez-Abarca
}

\begin{abstract}
This paper proposes a system for management of industrial production elements inspired by the techniques employed in the management of the current and complex ICT infrastructures on which business models are based and which are having considerable success. The main result of applying these techniques is that, at the same time as providing an adequate focus for the management of this type of infrastructure, it is possible to evolve from mass production models towards mass customization models increasingly bringing organisation objectives closer to the interests and requirements of customers. In this work, we present a review of the technologies in the sectors involved; a reconfiguration system is proposed for production systems based on management of ICT and integrated with the business system; their implementation and operation is analysed; and finally the main conclusions are drawn from the work, together with an indication of future lines of research.
\end{abstract}

\section{INTRODUCTION}

$\mathrm{T}$ HE market is increasingly demanding personalised products in order to satisfy customer requirements and specifically tailored manufacturing is shown to be one of the most effective channels for lowering costs and amortising the high investment required by these new approaches.

Internet and the use which organisation and customers make of it increasingly encourages this trend enabling rapid, global and personalised access to an increasingly wide and varied catalogue of products.

The solution is to be found in new business models such as agile manufacturing - systems with a high capacity for flexibility and drive which enables a rapid adaptation of production based on market demand.

Although ICT may also be a valuable tool for achieving these objectives, provided that they are put to service of the business, providing the functionality required, however without increasing the complexity of system processes or maintenance.

This paper proposes a system of network node regeneration (sections III and VI) based on IT technologies

Manuscript received January 25, 2007. This work was supported by the Ministerio de Educación y Cienci, Spain, under Grant TIN2006-04081.

D. Marcos-Jorquera, F. Maciá-Pérez, V. Gilart-Iglesias and J. A. GilMartínez-Abarca are with the Department of Computer Technology, University of Alicante. Carretera San Vicente s/n. 03690 San Vicente (Alicante). Spain. Email: \{dmarcos,pmacia,vgilart,gil\}@dtic.ua.es which will enable dynamic reconfiguration of the production elements, providing toughness and above all the flexibility required for implementing new business models.

The regeneration system has been devised as part of a more global model (section V) proposed as a template which will determine how to specify, design and implement management systems for production resources based on the ICT so that using these systems does not imply a need to implement and maintain new services and ICT infrastructures, but rather they may be carried out in a way that is fully integrated with the organisation's existing services and infrastructures.

A review of the state of the art is also presented together with the model and the system in related aspects (section II) an analysis of the scope of application (section IV) a tracing of the reconfiguration of equipment (section VII) and the main conclusions arising from the work such as future lines of work (section VIII).

\section{BACKGROUND}

Agile manufacturing may be defined as a production model integrating technology, human resources and organisation through ICT which provide flexibility, speed, quality and efficiency and enable a deliberate, effective and coordinated response to changes in the environment. This production model is the one which is best adapted to new requirements deriving mainly from Internet and ICT [1]. Either through models or techniques such as flexible manufacturing, mass customization or lean production it is necessary to seek means which will provide systems with greater flexibility for adapting in a dynamic way to changes and which will enable them to be integrated with existing elements of the organisation in order to achieve global management.

The literature on this matter has provided numerous contributions as well as very different approaches such as the use of intelligent control systems [2], the advantages of agent technologies, [3] or effects deriving from the development of ICT [4], all of which indicate the considerable interest that the scientific community has shown in these matters.

In order to address these changes with guarantees of success new production models are emerging, the principal 
requirements of which are based on achieving tough, scalable and reconfigurable systems using simple and transparent processes. Flexible systems play an important part in these models.

Flexibility is a characteristic which needs to be fulfilled in different sectors within a manufacturing organisation. We can find flexibility in: machinery, production, mixing, product range, production volumes, delivery, routing, expansion and response [5]. The common denominator in this type of approach is the need for models which will provide adaptability, agility, capacity for integration, dynamism, tolerance of faults, continuity of business and scalability.

One of the main fronts open in this field is the integration of production processes with other business processes. Due to physical and technological restrictions, production processes have been unable to reach the desired levels of integration and automation, and have to be considered in most cases as legacy systems. Luckily, progress has been achieved though various and extremely diverse proposals. The first of these were based on traditional models of automation based on proprietary protocols situated at an eBusiness model level of resources, as systems external to business processes (Modbus, Profibus, AS-I, FIPIO, DeviceNET, Interbus or Ethernet industrial), and consisted of initial attempts to facilitate integration with business components [6]. In other cases, as in Schneider's proposal [7], embedded devices were used (with Ethernet connection, TCP/IP support and including an integrated web server) under concepts such as transparent factory. Other manufacturers, such as ABB, went a little further raising communication to higher levels of organisation using the SOAP protocol, and incorporating intelligence, self-management and pro-activity and their embedded devices [8]. Along the same lines, [9] the use of WebServices is proposed as a normalised means of accessing functionalities of the devices and for integrating them in planning systems for business resources (ERP). In [10] it is proposed to benefit from these same techniques in order to raise the level of abstraction of the production elements to the business level in such a way that the integration of resources, processes and in general business logic is produced in a natural and transparent manner within the existing business models. Finally, also within the framework of European research projects there are some important initiatives which support the interest along these lines, with significant results which have advanced towards Service-oriented architecture (SOA) and embedded devices in industrial machinery as valid technologies [11] [12] [13].

The incorporation of management systems in industry began during the nineties with the use of more open and flexible control mechanisms which improved provisions of programmable automation [6]. Although the power and connectivity of these new components have been facilitating integration at all levels of the manufacturing process [14], their indiscriminate or poorly planned application, lack of standards and their inherent complexity have generated a new problem, namely their management [12].

The first open standards which attempted to address the management of devices in a generic manner were SNMP and CMIP [15], specified by the IETF; both protocols are oriented mainly towards network supervision and control.

The numerous tasks associated with network management, as well as the fact that it is extremely diverse and complex, means that maintenance work on these systems presupposes a high cost to organisations both in terms of time and personnel resources. Many companies use administration systems which incorporate the characteristics of self management and self configuration which facilitate network management [15]. Examples of these systems are: Solstice, Sun Enterprise Manager and NESTOR.

The use of multi-agent systems for computer network management provides a series of characteristics which favour automation and self-regulation in maintenance processes [16]. The creation of projects such as AgentLink III, the first Coordinated Action on Agent Based Computation financed by the European Commission 6th Framework Programme is a clear indicator of the considerable degree of interest currently manifested in software agents.

Among existing maintenance systems, high availability, disaster recovery and self management systems apply techniques which aim to avoid or at least reduce down time caused by failures or incidents in the services offered [17], which permit full restoration of equipment information within time constraints. With these mechanisms problems arising from degradation or loss of stored information can be resolved and they also facilitate the start up of new equipment replicating the information obtained on the basis of a similar model.

There are currently various regeneration systems in the commercial sector which include : Ghost from Symantec and REMBO; as open code projects: Clonezilla, G4L, Linbox y UDP Cast [18]. The main disadvantage of all these systems is their high dependency on technology to be recovered. This means that multiple solutions need to be applied to cover the range of technology in the organisation. The Department of Computer Technology of the University of Alicante has developed Gaia [19], a multiplatform regeneration system based on open code. The main disadvantage of this proposal is that its excessively open approach, although perfectly adequate for our research purposes, makes it at present a rather complex tool for commercial use. 


\section{PROPOSAL FOR A RECONFIGURATION SYSTEM}

The proposal is based on a reconfiguration system for industrial production elements based on a system of regeneration and management of computer equipment [19], which provides the possibility of installing, maintaining, updating and reconfiguring production elements, acting on either embedded or external computer control systems which regulate industrial machinery.

The immediate advantages of these proposals are:

- The application of ICT methods to achieve management and self management of production elements.

- Reduction of configuration times and set up of industrial machinery avoiding manual configurations.

- Dynamic adaptation to production changes.

- Reduction of set up times for new devices in the event of substitution through failure or extension.

The system is designed to facilitate adaptation of an organisation to new production models characterised by a changing dynamic environment requiring new approaches to business management and organisation [1]. It has been devised within a more general model which determines how to specify, design and implement management systems for industrial elements maintaining the simplicity of management tasks and achieving integration of processes.

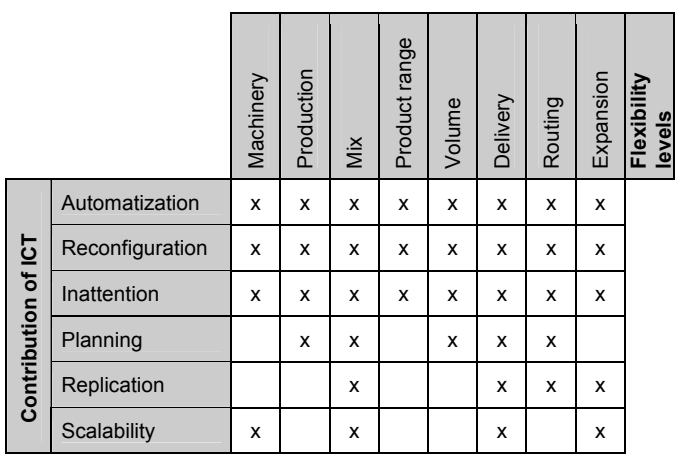

Fig. 1. Relation among the different levels of flexibility existent in manufacturing organizations and the contribution of ICT to the same.

Our proposal focuses on increasing flexibility of existing Flexible Manufacturing Systems (FMS), systems based on the concept of agile manufacturing described in section II. FMS are generally conditioned on electronics and therefore the level of abstraction provided by the incorporation of ICT in their management is fundamental to achieve the required levels of flexibility in production processes.

Figure 1 shows a table with the main contributions which these new technologies can bring at the different flexibility levels arising in manufacturing organisations.

\section{SCOPE OF APPLICATION}

The system is designed for the management of industrial

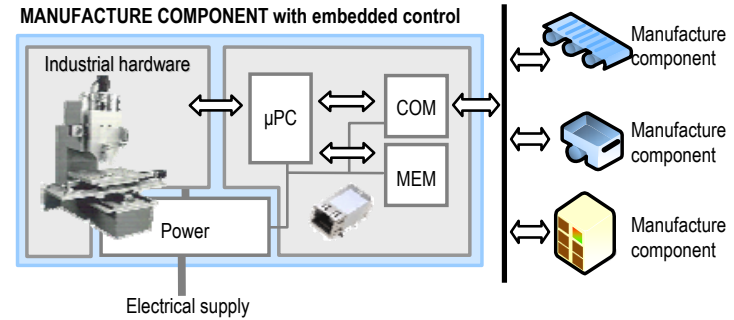

Fig. 2. Hardware architecture of the manufacture components. machinery and other auxiliary intermediate elements. The scope of manufacturing involves a variety of different devices. Based on their computational complexity they may be classified as:

- Low level elements: devices without an open computer system, based mainly on electronic control systems using cabling technology with a connection interface of varying degrees of complexity or configurability (CNC, PLC, industrial machinery.).

- Mid level elements: machinery or control elements which have an integrated computational platform. This platform is not based on complex ICT paradigms and is merely a high level interface for accessing the functionality of the device in question.

- High level elements: machinery which incorporates middleware platforms using emerging ICT paradigms (OO, SOA, agents, HTTP, etc). This enables the execution of more complex software and also its performance may be proactive in terms of other systems and the status of the environment in which it operates.

In order to enable manufacturing elements to interact with the remainder of the system we should ensure that they have network communication capacity as well as processing capacity to execute the required software for carrying out the reconfiguration tasks.

In the case of low level machinery, in order to achieve the proposal objectives, it is possible to incorporate embedded systems which provide a minimum computation and communication platform making it possible to interact with the reconfiguration system (see fig. 2). This same strategy could be applied in the case of industrial machinery which has a software platform based on the closed proprietary system.

\section{MANAGEMENT MODEL IN INDUSTRIAL ENVIRONMENTS}

The reconfiguration system proposed has been designed as part of a more general model as a template for specifying and implementing systems based on new technologies for management of production elements. This model also aims to ensure that the tasks incorporated in these new environments do not increase the overall complexity of production systems and that they may be considered within the global business model integrated in its process map. 


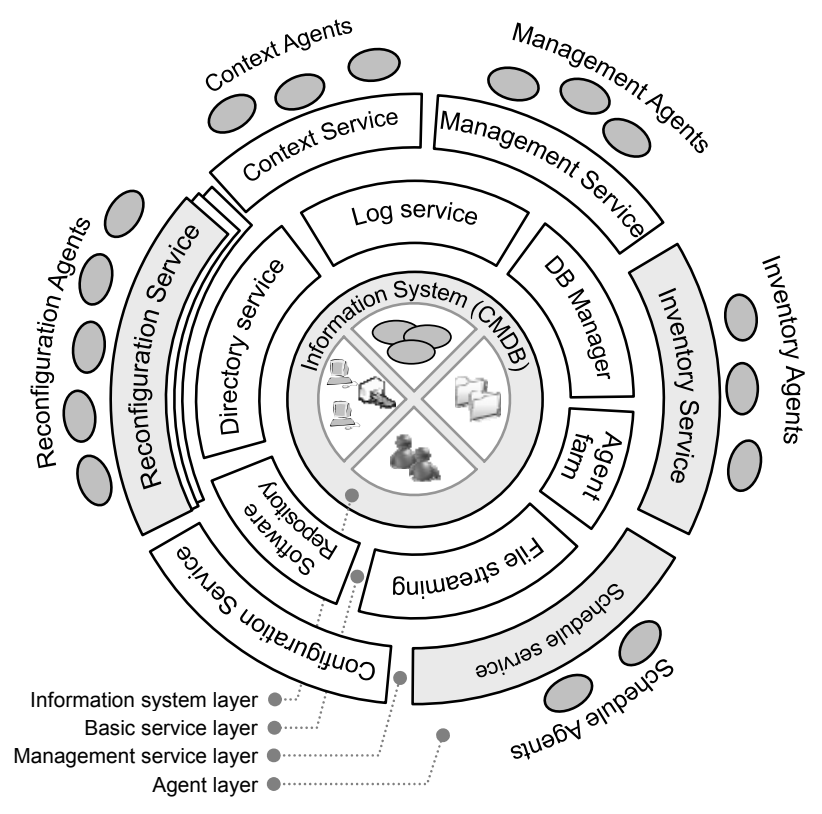

Fig. 3. Architecture of services.

The proposed architecture has a layered structure (see figure 3). The first layer contains the information system as a central core of the system. It is responsible for compiling all the information relating to the services provided as well as any additional information on the different organisation resources, enabling all types of maintenance processes to be automated. This system acts as a ConfigurationManagement Database (CMDB), offering a unified vision of all the organisation information. Overall the information system should be part of the organisation's global information service, avoiding the duplication of information, processes for obtaining information and maintenance and the resources employed to provide support. Some of the most important elements managed are: inventory of equipment and applications, agents and software repository, or user directories.

The two following layers are service layers: basic service layer and management service layer. The first one provides distributed services of a general nature, destined to provide support to the whole system: directory, register or database management services. The management services layer consists of management services. Some of these are more generic in nature such as configuration and system management services, whereas others provide a specific functionality which needs to be incorporated in manufacturing elements, such as the dynamic reconfiguration of the machinery.

The fourth and final layer (agent layer) contains the software agents responsible for executing machinery maintenance tasks. The agents provide a normalised service interface and facilitate the incorporation of characteristics such as pro-activity, autonomy, scalability, ubiquity and support for heterogeneity.

This conceptual model is based physically on a distributed architecture of n-levels. The basis of this architecture is the communications network. All the elements detailed in the conceptual model (contained in figure 3) would be located in the application layer of this physical architecture. The basic service layers represent network services and are located in specific servers. The management services layer takes the form of distributed software components or services and the multi-agent system concerns agent containers in network servers in the case of general services, or agent containers located in the actual production elements to be managed

The model also proposes a method for integrating management tasks within the global model of the organisation (see figure 4). The first step consists of modelling these tasks (scripts, applications or modules) as processes, following the same methodology used for the remaining business processes, like then standards of quality management systems ISO 9001 and EFQM.

Having defined the new processes, the associated software agent will be assigned to each task as responsible.

The new business processes will be included in the general processes map. Therefore, the workflow will need to be readjusted to any processes in the general model which have been seen to be affected

Using the new process map and based on the SOA

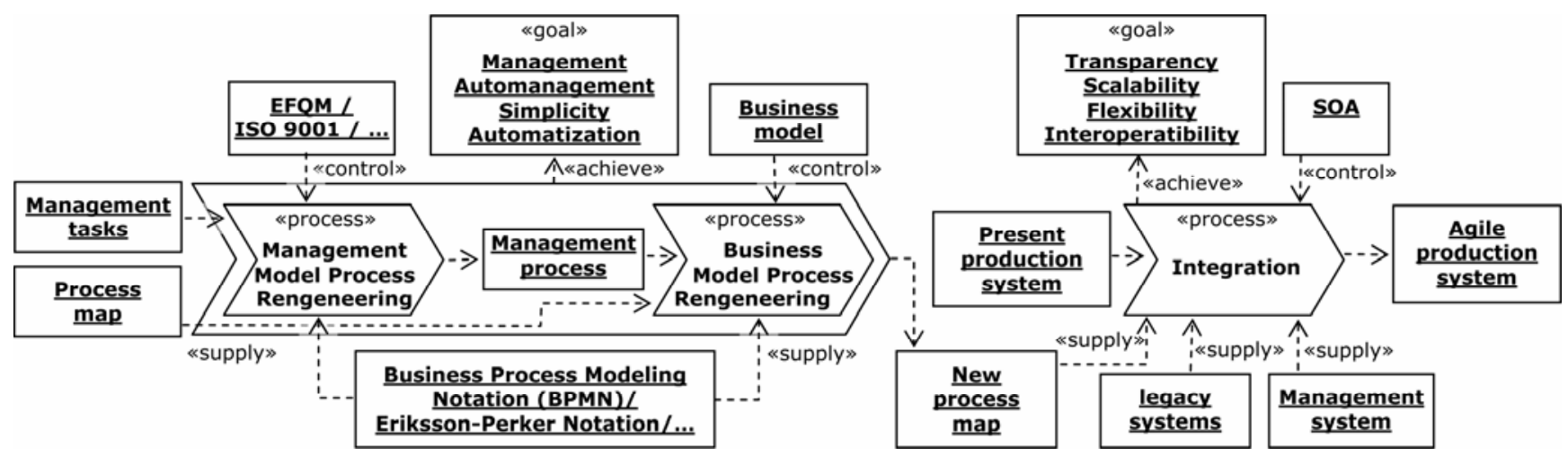

Fig. 4. Integration Process Model 
methodology, the final step of the model consists of incorporating the management system within the organisation production system. For this purpose it is proposed to create a service layer which encapsulates the business logic of the management system and the inherited systems and which, through orchestration, permits the composition of more complex services which implement the work flow for each business process.

\section{COMPONENTS OF THE RECONFIGURATION SYSTEM}

This section concerns the specification of reconfiguration within the model presented in the previous section. Conceptually, any management service comprises a multi-agent system and a group of auxiliary services.

Although the reconfiguration system is largely supported by the general services of the system, some of these stand out in particular (highlighted in grey in figure 3): the planning service which is responsible for registering and programming the tasks of different agents involved in the reconfiguration service; the inventory service providing all the information on the hardware and software configuration

TABLE I

ASSOCIATED TASKS WITH THE RECONFIGURATION SERVICE.

\begin{tabular}{ll}
\hline Name & Description \\
\hline wake_up & $\begin{array}{l}\text { Wake up a manufacture component starting his boot } \\
\text { process sending a special network datagram like WoL }\end{array}$ \\
\hline get_configuration & $\begin{array}{l}\text { Obtains the stored configuration of a manufacture } \\
\text { component }\end{array}$ \\
\hline put_configuración & Stores the configuration of a manufacture component \\
\hline get_agente & $\begin{array}{l}\text { Transfers an agent from the agent farm to the manufacture } \\
\text { component }\end{array}$ \\
\hline configure & Configure a manufacture component \\
\hline get_management_plan & $\begin{array}{l}\text { Obtains the maintenance plan for a manufacture } \\
\text { component }\end{array}$ \\
\hline init agent & Starts the functionality of an agent \\
\hline get_next_production_order & Gets the next production order to process \\
\hline put_logs & Stores the activity logs \\
\hline shutdown & Shutdown or reboot a manufacture component \\
\hline
\end{tabular}

TABLE II

ROLES OF AGENTS IMPLICATED IN RECONFIGURATION.

\begin{tabular}{lll}
\hline ID & Role & Goal \\
\hline RCN & Reconfiguration & Reconfiguring a manufacturing component \\
\hline INV & Inventory & Storing and giving access to the system information \\
\hline MOV & Mobility & Transferring the agent for the system \\
\hline INT & Interaction & Interacting with administrators \\
\hline PLN & Planning & Planning and triggering the reconfiguration process \\
\hline GST & Management & Managing the parameters of the system \\
\hline CNT & Context & Establishing the context for an agent \\
\hline
\end{tabular}

TABLE III

AGENTS IMPLICATED IN RECONFIGURATION.

\begin{tabular}{|c|c|c|c|c|c|c|c|c|}
\hline Id & Agent & Roles & $\begin{array}{l}\text { Relation with } \\
\text { other agents }\end{array}$ & Access to services & MB & MEM & AUT & LC \\
\hline $\mathrm{RA}$ & Reconfiguration & $\begin{array}{l}\text { RCN } \\
\text { MOV }\end{array}$ & $\begin{array}{l}\text { IA } \\
\text { CNT } \\
\end{array}$ & $\begin{array}{l}\text { Reconfiguration } \\
\text { Log }\end{array}$ & $\Delta$ & $\nabla$ & $\Delta$ & $\nabla$ \\
\hline$\overline{\mathrm{SA}}$ & Schedule & PLN & $\begin{array}{ll}\text { IA } \\
\text { CNT }\end{array}$ & $\begin{array}{l}\text { Inventory } \\
\text { Configuration }\end{array}$ & $\nabla$ & - & $\Delta$ & $\Delta$ \\
\hline$\overline{\mathrm{IA}}$ & Inventory & $\begin{array}{l}\text { INV } \\
\text { MOV }\end{array}$ & CNT & $\begin{array}{l}\text { Inventory } \\
\text { Repository } \\
\text { Configuration }\end{array}$ & - & $\Delta$ & - & - \\
\hline$\overline{\mathrm{MA}}$ & Management & $\begin{array}{l}\text { GST } \\
\text { MOV } \\
\text { INT }\end{array}$ & $\begin{array}{l}\text { SA } \\
\text { IA } \\
\text { CNT }\end{array}$ & $\begin{array}{l}\text { Repository } \\
\text { Configuration }\end{array}$ & $\Delta$ & $\boldsymbol{\nabla}$ & $\boldsymbol{\nabla}$ & - \\
\hline$\overline{\mathrm{CA}}$ & Context & $\begin{array}{l}\text { CNT } \\
\text { MOV }\end{array}$ & & $\begin{array}{l}\text { Context } \\
\text { Configuration }\end{array}$ & $\Delta$ & - & - & $\nabla$ \\
\hline
\end{tabular}

of all the equipment to be managed; the reconfiguration service which provides all the specific utilities for developing its function.

The multi-agent system is fundamentally defined by the group of tasks, together with the software agents which execute them. Table 1 shows a list summarising the main tasks relating to the reconfiguration of a manufacturing element. Table 2 identifies the different roles which the agents may adopt. Table 3 shows the main agents involved in the reconfiguration together with the relation between the agents.

\section{RECONFIGURATION PROCESS}

By applying the reconfiguration system proposed it is possible to automate the reorganisation of machinery in a manufacturing plant in order to manufacture a new product. The tasks associated with executing the reconfiguration in an autonomous and self regulating manner will be the agents in the system always supported by the other auxiliary services.

The agents are deployed at the request of the machinery itself of on the initiative of the system, according to prior planning.

On specific occasions, such for example when a piece of equipment needs to be regenerated literally from zero, a minimum platform is required so that the agents can carry out their work. In these cases prior to beginning any management task a context agent will be sent which will be responsible for providing the appropriate middleware for the rest of the agents. In order to carry out this operation the manufacturing element will need to be reinitiated. Having completed the boot process the equipment carries out an agent request using techniques such as PXE, where the network interface is responsible for getting a minimal network configuration and getting a specific boot agent. In this case the agent will contain everything necessary for its execution, including an embedded operating system.

When the equipment has an operative agents platform it is able to transfer a reconfiguration agent which will execute the maintenance tasks. The reconfiguration agent takes control of the manufacturing element, executes the basic initial verification and configuration tasks and requests, through a planning agent its work plan which it then immediately proceeds to carry out.

This work plan may include tasks such as the modification of specific configuration files of the manufacturing element or the direct reconfiguration of the device using specific instructions.

Figure 5 shows a sequence diagram of the reconfiguration process of a manufacturing element. 


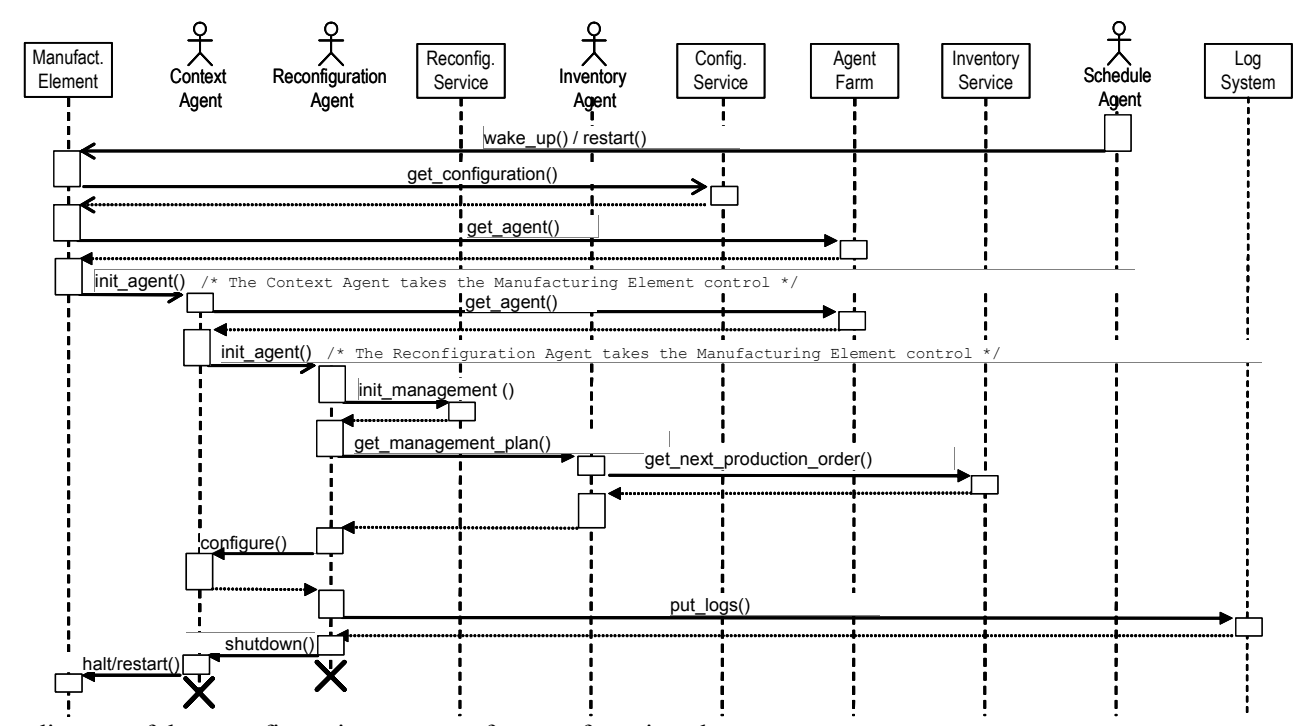

Fig. 5. Sequence diagram of the reconfiguration process of a manufacturing element.

\section{CONCLUSIONS}

In this paper we have justified the advantages of integrating production elements within the global organisation model in order to achieve the viability of new agile manufacturing models.

The research centred on proposing a model which will enable sophisticated ICT services to be fully integrated at production levels with the remaining technological elements, and in alignment with the existing business model. On the basis of this model a dynamic regeneration and reconfiguration system has been specified which facilitates the self regulating management of these elements and the associated processes, incorporating a high degree of flexibility and robustness at the levels involved.

The next step consists of incorporating semantics in the definition of services in a manner which will secure high levels of self configuration and self management for production elements.

\section{REFERENCES}

[1] L. Avella y D. Vázquez. Is Agile Manufacturing a New Production Paradigm? Universia Business Review, ISSN 1698-5117, № 6, pp. 94-107, 2005.

[2] R. W. Brennan, M. Fletcher y D.H. Norrie. An Agent-Based Approach to Reconfiguration of Real-Time Distributed Control Systems. IEEE Transactions on Robotics and Automation, Vol. 18, $\mathrm{N}^{\circ} 4,2002$.

[3] A. Giret, V. Julián y V.J. Botti. Agentes Software y Sistemas MultiAgente: Conceptos, arquitecturas y aplicaciones. Aplicaciones Industriales de los sistemas Multiagentes. Pearson Prentice Hall, ISBN : 84-205-4367-5, 2005

[4] D.C. McFarlane, S. Bussmann: Developments in Holonic Production Planning and Control, in: Int. Journal of Production Planning and Control, Vol. 11, No. 6, 2000, pp. 522 - 536.

[5] N. Slack. The flexibility of manufacturing systems. International Journal of Operations \& Production Management Vol. 25 No. 12, 2005 pp. 1190-1200.

[6] R.P. Moreno. Ingeniería de la automatización industrial. Ra-Ma, Madrid, Spain, 2004
[7] Transparent Factory. Manual de usuario y planificación. [Online] Available: http://www.modicon.com, 2001.

[8] U. Topp, P. Müller. Web based service for embedded devices. International Workshop on Web Service: Research, Standardization and Deployment (WS-RSD'02). Lecture notes in computer science. Web, Web Service and Database Systems. Pag. 141-153, 2002.

[9] A.P. Kalogeras, J.V. Gialelis, C.E. Alexakos, M.J. Georgoudakis, S.A. Koubias. Vertical integration of enterprise industrial systems utilizing Web Service. Proceedings of the 5th IEEE International Workshop on Factory Communication System (WFCS 2004), Technical University of Vienna, Vienna, Austria, 22-24 September 2004.

[10] V. Gilart-Iglesias, F. Maciá-Pérez, J.A. Gil-Martínez-Abarca y A. Capella-D'alton. Industrial Machines as a Service: A model based on embedded devices and Web Services. 4th International IEEE Conference on Industrial Informatics (INDIN'06), 2006, pp. 630-635.

[11] The SIRENA project. [Online] Available: http://www.sirena-itea.org

[12] F. Jammes, H. Smit. Service-Oriented paradigms in industrial automation. IEEE Transaction on industrial informatics. VOL I. $\mathrm{n}^{\circ} 1$. Pag. 62-70. 2005.

[13] F. Jammes, H. Smit, J.L. Martinez-Lastra, I.M. Delamer Orchestration of Service-Oriented Manufacturing Processes. Proc. of the 10th IEEE International Conference on Emerging Technologies and Factory Automation, ETFA 2005, Catania, Italy, September 1922.

[14] Chang H. A Model of Computerization of Manufacturing Systems: an International Study. Information and Management 39 7:605-624. 2002.

[15] Kim M, Choi M, Hong JW.A load cluster management system using SNMP and web. International Journal of Network Management. 2002. 12 6: 367-378

[16] Guo J, Liao Y, Parviz B (2005) An Agent-based Network Management System. In Hamza HM (eds). Internet and Multimedia Systems and Applications (IMSA 2005), Honolulu, pp 20-88

[17] Ivinskis K. High availability of commercial applications. In Carey M, Schneider D (eds).Proceedings of the 1995 ACM SIGMOD international conference on Management of data, ACM Press, New York, pp 433-434.

[18] Cuff JA, Coates GMP, Cutts TJR, Rae M (2004) The Ensembl Computing Architecture. In Genome Research, Cold Spring Harbor Laboratory Press 14: 971-975.

[19] D. Marcos Jorquera, F. Maciá Pérez, V. Gilart Iglesias y J.A.. Gil Martínez-Abarca. High Availability for Manufacturing Components. 2006 IEEE International Conference on Industrial Informatics, pp 474-479. 